\title{
Conflitos em espaços globalizados: uma leitura das resistências na Microrregião de Campos dos Goytacazes/RJ
}

\section{Conflicts in globalized spaces: a reading of resistances in the micro- region of Campos dos Goytacazes/RJ}

Érica Teręinha Vieira de Almeida - Doutorado em Serviço Social pela Universidade Federal do Rio de Janeiro (UFRJ). Professora do Departamento de Serviço Social de Campos e do Programa de Pós-graduação em Desenvolvimento Regional, Ambiente e Políticas Públicas, da Universidade Federal Fluminense (UFF). E-mail: ericalmeida@uol.com.br

José Luis Vianna da Cruz - Doutorado em Planejamento Urbano e Regional pela Universidade Federal do Rio de Janeiro (UFRJ). Professor do Programa de Pós-graduação em Desenvolvimento Regional, Ambiente e Políticas Públicas da Universidade Federal Fluminense (UFF). E-mail: joseluisvianna@uol.com.br

\section{Resumo}

$\mathrm{O}$ artigo analisa dois conflitos na Microrregião de Campos dos Goytacazes, no Norte do estado do Rio de Janeiro, decorrentes dos impactos de Grandes Investimentos (GIs) e das resistências protagonizadas pelos atores afetados por dois GIs. O resultado das pesquisas dos autores está sustentado metodologicamente nas pesquisas bibliográfica, documental e hemerográfica. A escolha dos conflitos deve-se a suas vinculações com os GIs: diretas, como a expropriação de pequenos agricultores para a instalação de um megaporto, em São João da Barra; e indiretas, como a remoção dos moradores da maior favela de Campos dos Goytacazes, realizada pela prefeitura na condução do seu programa de habitação popular. O objetivo é identificar, num determinado território, as forças sociais e políticas que se articulam na implantação dos GIs, e como atuam, bem como as mediações que viabilizam as resistências dos grupos sociais afetados aos processos de subordinação dos espaços à dinâmica capitalista global.

\section{Palavras-chave}

Grandes Projetos. Conflitos. Resistências. Integração Internacional. Microrregião de Campos dos Goytacazes.

\begin{abstract}
The article analyzes two conflicts in the micro-region of the municipality of Campos dos Goytacazes, in northern Rio de Janeiro State, Brazil, arising from the impacts of Large Investments (LIs) and resistance by the actors affected by two LIs. The result of the authors' research is methodologically supported by bibliographical, documental, and hemerographic sources. The conflicts approached were picked regarding their links with the LIs, either directly, such as the expropriation of small farmers to install a mega-port, in the municipality of São João da Barra, Rio de Janeiro State, Brazil; or indirectly, as the removal of residents from the largest slum in Campos dos Goytacazes carried out by the City Hall as part of its popular housing program. The aim is to identify, in a given territory, the social and political forces articulated in the implementation of such LIs and the way they act, as well as the mediations that enable the resistance of the social groups affected to the processes of subordination of spaces to the global capitalist dynamics.
\end{abstract}

\section{Keywords}

Large Projects. Conflicts. Resistance. International Integration. Campos dos Goytacazes micro-region. 


\section{INTRODUÇÃO}

A construção deste artigo teve como motivação principal a divulgação dos achados das pesquisas dos autores ${ }^{1}$, ambas com foco na configuração socioespacial da Microrregião de Campos dos Goytacazes² (Figura 1), a partir da consolidação e expansão dos Grandes Projetos de Investimento (GIs), da Exploração e Produção (E\&P) de petróleo e gás; e da implementação do Porto do Açu. Ao problematizar o processo recente de integração deste território na estratégia de inserção do Brasil na economia internacional, também sob a perspectiva dos conflitos, as pesquisas possibilitaram a construção da sua cartografia na Região, oferecendo elementos quanto à sua espacialidade, aos sujeitos envolvidos e aos interesses e motivações em disputa. Essa modernização mais contemporânea articula, de modo conflitivo, os elementos de duas dinâmicas: a dinâmica socioeconômica e político-cultural dessa Região, comandada historicamente pelas elites da agroindústria sucroalcooleira; e o novo regime de acumulação mundial, sob o comando da burguesia financeira mundial (CHESNAIS, 2003) e hegemonia neoliberal, com seus impactos socioespaciais.

A partir da segunda metade da década de 2000, diversos Grandes Investimentos $^{3}$ vão aportar no País, particularmente em infraestrutura. Esses investimentos são viabilizados, em sua maior parte, por recursos federais, isoladamente ou em parcerias com o capital privado, uma vez que se inscrevem na estratégia de inserção do País na economia internacional. Cabe lembrar que o Brasil se tornou um dos maiores exportadores mundiais de produtos minerais e agroindustriais, acentuando, ainda mais, o processo de reprimarização da economia. O território foi tomado por grandes obras de infraestrutura, como ferrovias, rodovias, hidrelétricas e portos, viabilizando a expansão da fronteira da agropecuária e da mineração, em especial, bem como de outros negócios, em

\footnotetext{
Erica T. V. Almeida: “Trabalho, Precarização e Resistência na periferia do capitalismo - a Região Norte Fluminense (NF) como cenário", que teve como finalidade articular as lutas sociais e as resistências no NF ao contexto de integração da região à economia mundial, capitaneada pelos grandes investimentos (GIs), com apoio de Bolsas de Iniciação Científica da FAPERJ e do PIBIC; e José Luis V. Cruz: "O Norte, o Noroeste Fluminense, as Baixadas Litorâneas e o Complexo de Exploração e Produção de Petróleo e Gás: dinâmica socioeconômica, mercado de trabalho, desenvolvimento regional e gestão territorial", com apoio da FAPERJ.

2 A microrregião de Campos dos Goytacazes integra a Região Norte Fluminense. É formada pelos municípios de Campos dos Goytacazes - que dá nome à microrregião pela sua centralidade e relevância -, São João da Barra, São Francisco de Itabapoana, São Fidélis e Cardoso Moreira. Esta microrregião, junto com a microrregião de Macaé, compõe a Região Norte Fluminense.

3 Os Grandes Investimentos são investimentos públicos e privados de grande porte, em termos de capital, da área e da importância, em valores absolutos e relativos, no segmento a que estão ligados, e da capacidade de impacto no ambiente natural e construído (VAINER, 2007).
} 
direção às áreas de populações tradicionais. Este modelo de desenvolvimento, ancorado na exportação de commodities, favoreceu as práticas de destruição ambiental e a violência contra os povos tradicionais.

Figura 1 - Região Norte Fluminense, com destaque para os municípios que compõem a Microrregião de Campos dos Goytacazes

\section{REGIÄO NORTE FLUMINENSE} MUNICIPIOS

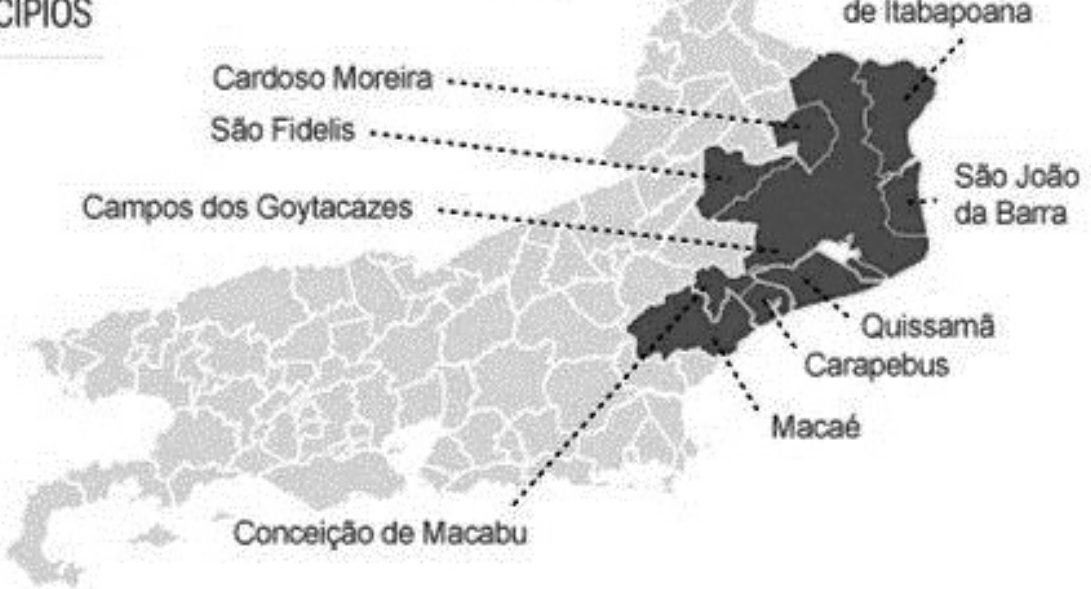

Fonte: Galdo (2014).

A implantação de novos portos no litoral do País, com o intuito de escoar as commodities, não deixou menos sequelas. Foram centenas de deslocamentos forçados de norte a sul, ilustrando o novo padrão de desenvolvimento e as similitudes quanto aos impactos sociais e ambientais produzidos nos territórios. Localizada na Mesorregião Norte Fluminense, no estado do Rio de Janeiro, a Microrregião de Campos dos Goytacazes (Figura 1) vem experimentando, há pouco mais de 40 anos, um processo de transformações radicais na sua dinâmica socioeconômica e político-cultural. Após séculos de destacada atividade de monocultura agroindustrial da cana-de-açúcar, iniciou-se, em 1978, na Região Norte Fluminense (NF), a produção de petróleo offshore na sua plataforma continental, denominada Bacia de Campos, em referência ao seu município-polo tradicional. No final dos anos 1990, a produção da Bacia de Campos alcançou 80\% da produção nacional de petróleo.

Em 1997, foi sancionada a Lei no 9.478, denominada Lei do Petróleo (BRASIL, 1997), que extinguiu o monopólio estatal da Petrobras na E\&P de petróleo e gás e, em contrapartida, dobrou o percentual dos royalties, parcela 
devida pelas empresas da produção por poço, e instituiu as Participações Especiais, que constituem um adicional sobre a produção dos poços mais rentáveis. Um pequeno número de municípios privilegiados passou a receber valores extremamente elevados, situando-os entre os municípios de maior orçamento per capita - em alguns casos, também em valores absolutos - do País (PIQUET; CRUZ; VILANI, 2013).

Paralelamente, em 2007, iniciou-se, no NF, a construção do Porto do Açu, um empreendimento privado, com apoio e subsídios públicos, no município de São João da Barra, na Microrregião de Campos dos Goytacazes ${ }^{4}$. Trata-se de um porto-indústria, com uma retroárea e uma área de Condomínio Industrial, constituindo um megaporto, para atender às demandas do comércio internacional de commodities, dado o porte dos navios que pode receber.

O fim do ciclo regional da agroindústria sucroalcooleira, a vigência do ciclo regional da indústria extrativa do petróleo e a adição do Complexo Portuário do Açu condicionam os impactos e as transformações territoriais, sociais, culturais, econômicas e políticas do espaço urbano-regional do NF e, especialmente, da Microrregião de Campos. Nesse processo, agravam-se antigos e novos conflitos conectados, direta e indiretamente, ao declínio do longo ciclo da monocultura da cana-de-açúcar e à emergência dos GIs aqui destacados — o Complexo de E\&P de petróleo e Gás e o Complexo Portuário do Açu.

Embora as pesquisas que sustentam esta reflexão tenham como recorte territorial a Mesorregião Norte Fluminense, este artigo prioriza os municípios de São João da Barra e de Campos dos Goytacazes, doravante denominado Campos, abordando os conflitos envolvendo os camponeses expropriados pelo governo do estado do Rio de Janeiro, em favor do Porto do Açu, e aqueles relativos à remoção dos moradores da Favela da Margem da Linha, atendendo aos interesses do mercado imobiliário. A escolha dos municípios foi orientada pelos resultados de uma pesquisa hemerográfica sobre conflitos e mobilizações coletivas, realizada pelo Jornal Folha da Manhã entre 2000 e $2017^{5}$.

4 O Porto do Açu inicialmente fazia parte do conglomerado do empresário Eike Batista. Com a sua crise, em 2012, passou a ser controlado pelo fundo americano EIG Prumo Fundo de Investimento em Participações Multiestratégia, que controla a Prumo Logística, com $76 \%$ das ações da empresa, em associação com o Fundo de Investimento Mubadala de Abu Dhabi, que detém 24\% dela (PORTOS E NAVIOS, 2019).

5 A pesquisa hemerográfica sobre conflitos e mobilizações coletivas nas Regiões Norte e Noroeste Fluminense fazia parte da pesquisa Trabalbo, Precarização e Resistência na periferia do capitalismo - a região Norte Fluminense (NF) como cenário, que contou com bolsas de pesquisa de IC/FAPERJ e UFF/PIBIC. A escolha do Jornal Folha da Manbã (impresso e on-line) como fonte desta pesquisa se deu em função da sua cobertura e circulação regionais, da sua vigência durante todo o período da pesquisa sobre mobilizações coletivas - de 2000 a 2017 - e pelo fato de ele representar um importante espaço de publicização dos conflitos na Região investigada. 
Para este artigo, além desse, foram utilizados outros veículos de comunicação como fonte de informação, assim como as produções bibliográficas, mormente as dissertações e teses que abordam tais conflitos. Os resultados desta pesquisa funcionaram como uma bússola, no sentido de orientar o aprofundamento, mediante pesquisa bibliográfica e documental, da análise sobre as relações entre esses dois conflitos e, portanto, da existência de uma ação coletiva organizada e articulada politicamente, em diferentes escalas, para fazer frente às ações dos GIs supracitados e seus impactos, especialmente aqueles relativos aos processos de expropriação violenta no campo e na cidade.

Como se articulam as forças sociais no território, para viabilizar as expropriações e desterritorializações necessárias aos GIs? Como se articulam os grupos sociais afetados pelos impactos negativos da implantação e operação dos GIs? Quais as escalas de articulação dos atores interessados na implantação dos GI e dos grupos afetados, na resistência aos impactos?

\section{CONFLITOS E AÇÃO COLETIVA: A MICRORREGIÃO DE CAMPOS DOS GOYTACAZES EM DISPUTA}

Conhecida historicamente pela monocultura da cana-de-açúcar e pela produção de açúcar e álcool, a Microrregião de Campos dos Goytacazes foi marcada pelo monopólio da ação política das elites regionais junto às instituições do Estado, o que produziu um território marcado por profundas desigualdades e pobreza e, ao mesmo tempo, por fortes vínculos clientelistas que sustentaram por décadas o "fechamento da região" por suas elites (CRUZ, 2003). A Região voltaria à cena nacional pela descoberta e exploração de petróleo e gás e pelo destaque dos seus municípios produtores, que tiveram seus orçamentos aumentados pelos royalties e participações especiais, quando passaram a ficar conhecidos como petrorrentistas ${ }^{6}$.

A partir da segunda metade dos anos de 1980, o agravamento da crise do setor sucroalcooleiro regional - com a concentração do segmento em São Paulo e no Centro-Sul - elevou, consideravelmente, os índices de desemprego na Microrregião, reforçados pelo aumento do desemprego em nível nacional, sob o governo neoliberal de Fernando Henrique Cardoso e sua política de ajuste fiscal. Destaque-se que mesmo a potente indústria petrolífera não teve condições de minimizar os impactos da crise do emprego, haja vista a sua incapacidade de

\footnotetext{
Denominação dada aos municípios "produtores" de petróleo altamente dependentes das rendas recebidas, porém sem a presença de atividades produtivas da indústria da cadeia do petróleo (PIQUET; CRUZ; VILANI, 2013).
} 
absorver aqueles a quem Cruz (2003) chamou de "deserdados da cana". Este grupo subalterno continuaria integrado de modo precarizado e desprotegido socialmente em atividades informais e mal remuneradas.

Por outro lado, o crescimento dos orçamentos dos municípios produtores de petróleo contribuiu para que se tornassem altamente dependentes dos recursos oriundo dos royalties e participações especiais, além de reforçar a cultura política clientelista praticada pelos políticos locais, recriando a figura dos antigos coronéis - hoje representada pelo poder conferido aos prefeitos -, fazendo com que o poder político transitasse da porteira das fazendas e das usinas para a porta da prefeitura (CRUZ, 2003). Esta última adquire capacidade financeira e política para fazer intervenções na vida urbana e, em especial, no cotidiano das classes subalternas, seja com programas de moradia popular e de infraestrutura em geral, seja com programas de transferência de renda, subsídios na passagem e obras de saneamento, construção de hospitais, e outras obras de valorização do espaço urbano; e, ainda, para propor alianças importantes com o setor privado e com frações da burguesia local, em especial aquelas ligadas aos setores agropecuários e da construção civil, reatualizando o conservadorismo.

A natureza populista dos governos pós-1988, em especial em Campos, vai se expressar na condução de uma política clientelista, centralizadora e autoritária, demandando um sistema articulado de mediadores (cabos eleitorais, vereadores, representantes do partido nos bairros), com o papel de manter essa política. As práticas voltadas para eliminar qualquer experiência de autonomia e de organização popular combinam, quase sempre, cooptação e coerção, produzindo prejuízos incalculáveis do ponto de vista da criação de experiências comuns e de práticas políticas de oposição ao clientelismo. Santos (1998) afirma que o populismo emudece o cidadão e paralisa a ampliação da consciência possível, na medida em que oferece resposta apenas às necessidades imediatas, mas não propõe nenhuma mudança para além, reproduzindo um vínculo extremamente perverso entre governo e necessitados, em contextos de cidadania incompleta, parcial e limitada.

Mais recentemente, a nova dinâmica socioeconômica e seus impactos vêm reconfigurando o padrão de conflitividade na Microrregião, sobretudo nos municípios de Campos e de São João da Barra. Os conflitos sociais são parte da ordem social que constituem, nos oferecendo a possibilidade empírica de abordar as contradições sociais (RAMOS, 2003). Nesse sentido, tendo como referência os resultados de Almeida e Carvalho (2019), observa-se que os sujeitos políticos coletivos que protagonizaram as lutas sociais e as resistências são forjados a partir da relação dialética entre o passado e o presente, reforçando a centralidade do legado da escravidão, da superexploração do trabalho e do "fechamento da 
região" pelas elites da agroindústria sucroalcooleira, assim como do legado das insurgências. Estas, mesmo minoritárias e incapazes de se constituírem em lutas contra-hegemônicas, vêm sendo reatualizadas pelos movimentos e coletivos negros em suas ações políticas contra a subalternidade no mundo do trabalho e na esfera pública.

Além disso, interessa destacar a hegemonia conquistada pelo neoliberalismo e sua legitimidade para impor as suas agendas econômica, cultural e jurídicopolítica. Ainda que em condições adversas, foram muitas as mobilizações coletivas, organizadas ou espontâneas, contrárias aos processos recentes de expropriação dos direitos sociais, em particular dos direitos do trabalho e ao trabalho, além das lutas pela reforma agrária protagonizadas pelo Movimento dos Trabalhadores Sem Terra (MST) - considerando o estoque de grandes extensões de terras ociosas, com o fim do ciclo da cana-de-açúcar em toda a Região Norte Fluminense (ALMEIDA; CARVALHO, 2019). Todavia, em função do pouco espaço deste artigo, serão priorizadas as resistências relacionadas às expropriações vinculadas aos GIs aqui tratados.

\subsection{O PORTO E AS EXPROPRIAÇÕES}

Um conflito típico da integração subordinada do Brasil no capitalismo globalizado e das estratégias de incorporações de novos ativos pela força do grande capital internacional (HARVEY, 2013) tem início com a instalação do Porto do Açu no município de São João da Barra, mais precisamente no seu $5^{\circ}$ Distrito. Este processo, que, segundo Costa (2018), resultou na expropriação de uma área de 7.036 ha pertencentes a 1.500 famílias de pequenos agricultores, tem início com o Decreto de desapropriação n ${ }^{\circ} 41.584$, de $2008^{7}$, assinado pelo então governador do Rio de Janeiro, Sérgio Cabral, em favor da Companhia de Desenvolvimento Industrial do estado do Rio de Janeiro (Codin/RJ). Esta, em seguida, cederia a área dos agricultores à empresa controladora do projeto do Complexo Industrial-Portuário do Açu (ainda de propriedade da LLX de Eike Batista), hoje Prumo Logística Global, não deixando dúvidas sobre o papel do governo nesta parceria.

\footnotetext{
O Decreto Estadual n ${ }^{\circ} 41.584$, de dezembro de 2008, declarou de utilidade pública, para fins de desapropriação, as terras na localidade do $5^{\circ}$ Distrito de São João da Barra, para implantação do Distrito Industrial. Em junho de 2009, o Decreto no 41.195 declarou de utilidade pública, para fins de desapropriação, novos imóveis dessa localidade. Logo depois, em agosto de 2009, o Decreto Estadual $n^{\circ} 41.998$ alterou o Decreto $n^{\circ} 41.584$, suprimindo algumas áreas, no que se refere ao Distrito Industrial. Importante destacar que, em um primeiro momento, os decretos transferem apenas a posse dos imóveis à Codin/RJ; a propriedade desses imóveis da Codin/RJ para a Empresa seria transferida apenas após o término das desapropriações.
} 
A expropriação das terras dos pequenos agricultores do Açu confirma o sentido dado por Harvey (2013) ao processo de acumulação por despossessão, em especial, no que se refere ao uso da violência. Segundo Costa (2018), foram inúmeras as atitudes de violação de direitos no processo de desapropriação dos camponeses do $5^{\circ}$ Distrito, com a ocorrência, quase cotidiana, de intimidações, coações e violências tanto por parte de pessoas ligadas ao Porto quanto daquelas vinculadas às instituições estaduais, como à Polícia Militar e à Codin/RJ.

Reginaldo lembrou outros tristes episódios consequentes da desapropriação, como colegas trabalhadores que morreram, entraram em depressão ou desenvolveram doenças graves, segundo ele ocasionadas pelo desgosto. $\mathrm{O}$ filho dele, de 4 anos, também tomou trauma de polícia depois de ver o pai ser levado à delegacia, ao tentar salvar um boi atolado em uma terra desapropriada. Fui preso porque tentei salvar uma vida e não tenho a menor vergonha disso (MARQUES, 2017a, não paginado).

Eles jogaram o gado em qualquer canto, destruíram toda a plantação, cercaram os 10 alqueires, abriram um valão em volta e proibiram a nossa entrada. Até hoje existem vigias no local, embora a terra esteja totalmente ociosa, contou. Segundo Adeilson, o que aconteceu em São João da Barra vai contra todas as ações de meio ambiente e direitos humanos. Falam tanto em preservação ambiental, mas secaram a Lagoa de Iquipari, mataram peixes, destruíram o lençol freático e esmagaram o povo (MARQUES, 2017a, não paginado).

A experiência de Juarez Alves da Silva não foi diferente:

Em 1988 eu comprei, legalmente e com muito esforço, dois alqueires de terra, onde construí minha casa e iniciei uma farta plantação de maxixe, quiabo e eucalipto para garantir a renda da família. De um dia para o outro, às 6h da manhã, bateram na minha porta, tombaram a casa com todos os móveis dentro, inclusive um dinheiro que eu tinha guardado; levaram meu carro; meu motor de irrigação; soltaram meu gado e, após sete minutos de resistência, me prenderam e me condenaram por desacato à autoridade (MARQUES, 2017b, não paginado).

Além de marcado pelas violações de direitos, o processo de expropriação implementado pelo Porto do Açu, em parceria com a Codin/RJ, expõe a presença do Estado, desde a origem do projeto até depois, na garantia da sua implementação, seja permitindo o não pagamento das indenizações ou o seu pagamento irrisório $^{8}$, seja operando na repressão e na intimidação dos agricultores

${ }_{8}$ Segundo o advogado Antônio Maurício Costa, autor de uma ação popular contra o governo do Estado, a LLX e a Prumo Logística Global, o ex-bilionário Eike Batista e o exgovernador do Rio de Janeiro, Sérgio Cabral, deram um prejuízo de mais de $\mathrm{R} \$ 2$ bilhões nas desapropriações no $5^{\circ}$ Distrito de São João da Barra. De acordo com o advogado, a origem desse prejuízo é que Batista, junto ao governo do Estado, não teria pagado as indenizações de acordo com a avaliação dos peritos judiciais. Isto é, o metro quadrado das 
pelo intermédio das suas instituições, particularmente a polícia militar. Segundo o presidente da Associação de Proprietários de Imóveis e Moradores do Açu (ASPRIN), Campo da Praia, Pipeiras, Barcelos e Cajueiro, "mais de 70\% dos produtores desapropriados também não receberam as indenizações prometidas" (MARQUES, 2017a, não paginado).

Sobre o grupo de 16 agricultores reassentados na Fazenda Palacete ${ }^{9}$, uma área do Grupo Othon, ainda em litígio, o presidente da ASPRIN afirma que:

Esses que foram indenizados não receberam a documentação das terras entregues e que ainda pertencem aos herdeiros do Grupo Othon. Essas terras entregues aos produtores foram arrendadas na Justiça do Trabalho em acordo entre o Grupo X e o Othon, mas o processo não foi finalizado", explicou. Ao todo, segundo o mesmo, foram 477 propriedades e 1408 lotes de terreno da praia desapropriados a partir do dia 31 de dezembro de 2008, quando a prefeita Carla Machado assinou o decreto que autorizou a tomada das terras em São João da Barra (MARQUES, 2017a, não paginado) ${ }^{10}$.

Além de não ter havido procedimento administrativo da Assembleia Legislativa do Estado do Rio de Janeiro, como prevê a lei, essa foi uma desapropriação forçada, de forma desumana e sem direito à negociação livre. Os produtores foram retirados das suas terras como se fossem criminosos e a assistência que prometeram não foi dada. [...] Com isso, muitos produtores foram obrigados a pedir abrigo nas casas de familiares, onde permanecem até hoje; foram para outras terras em municípios vizinhos; ou arrendaram outras propriedades para continuar produzindo (MARQUES, 2017a, não paginado).

A prisão do ex-governador do Rio de Janeiro, Sérgio Cabral (MDB), em novembro de 2016, em virtude dos desdobramentos da Operação Lava Jato, acabou contribuindo para esclarecer as irregularidades no processo de desapropriação das terras dos agricultores. Em depoimento ao Ministério Público Federal (MPF) em 2017, Cabral confessou que o governo recebeu U\$ 16 milhões de Eike Batista durante a campanha eleitoral, para desapropriar mais de 7 mil

terras foi avaliado em aproximadamente $\mathrm{R} \$ 25 / \mathrm{R} \$ 30$, mas a quantia paga teria sido de cerca de $\mathrm{R} \$ 0,25 / \mathrm{m}^{2}$. Isso significa que o empresário deveria pagar muito mais do que os R\$ 37 milhões previstos no contrato pelos $75 \mathrm{~km}^{2}$ desapropriados — embora só tenham sido quitados R\$ 5 milhões desse valor (MARQUES, 2017b).

9 A antiga fazenda Palacete, agora Vila da Terra, foi criada como espaço para o reassentamento compulsório dos agricultores e pescadores. Conta com 34 casas com uma pequena área de 2 ha no seu entorno. Além de não garantir a estrutura necessária para a produção agrícola, os reassentados foram orientados a não iniciarem suas culturas, em especial as culturas permanentes, já que as terras estão em litígio (COSTA, 2018, p. 44).

10 O presidente da ASPRIN refere-se à Lei Municipal 115/2008, assinada pela prefeita Carla Machado. Segundo Costa (2018), essa lei revisou a Lei Municipal 050/2006, que dispõe sobre o Plano Diretor Municipal de São João da Barra e estabelece o zoneamento do seu território, radicalizando as condições e possibilidades de sua ocupação ao converter quase $50 \%$ de sua área rural para o uso industrial. 
hectares de terras no $5^{\circ}$ Distrito de São João da Barra. Se muitos já desconfiavam dessa "troca de favores" entre o governador e a empresa LLX, o depoimento foi crucial, não só porque corrobora os argumentos dos camponeses sobre as irregularidades do processo, mas porque coloca em questão a função do Decreto de desapropriação, já que, segundo Barcelos, “apenas 10\% da área está sendo ocupada, deixando 90\% dela ociosa" (TAVARES, 2017, não paginado).

Passados 10 anos, as denúncias de corrupção - associadas ao fato de que $90 \%$ das terras desapropriadas ainda não tiveram utilidade para o Distrito Industrial, servindo como fonte de renda para a Prumo Global, via aluguel, como garantia futura para as empresas de apoio offshore - deram fôlego ao movimento de resistência dos camponeses, que organizaram um acampamento de 100 dias em suas antigas terras, para chamar atenção da sociedade e de outras instâncias do Estado (TAVARES, 2017) ${ }^{11}$. Em junho de 2017, os camponeses do Açu conseguiram uma primeira audiência pública na Assembleia do Estado do Rio de Janeiro (ERJ), com a participação de diversas instituições, entre elas a Defensoria Pública. Em sua participação, as defensoras públicas afirmaram que “dos 229 agricultores alvos de processos de desapropriação [...], menos de 5\% receberam o valor total. Além deles, um grupo de menos de $10 \%$ obteve $80 \%$ da quantia à qual têm direito" (AÇU..., 2017, não paginado).

Segundo Moraes (2013, não paginado):

[...] é possível deduzir que a incorporação imobiliária, fora o projeto da Cidade $\mathrm{X}$, se transformou num dos mais importantes itens de faturamento do grupo EBX, superior até a algumas atividades industriais e de logística que arrastam estas demais atividades projetadas para o Complexo do Açu ${ }^{12}$.

A área do Complexo Portuário do Açu - compreendendo o porto, a retroárea, o Distrito Industrial, a Vila da Terra e a reserva ambiental - totaliza cerca de $40 \%$ da área total do município. O último Plano Diretor, datado de

11 De acordo com Moraes, se for considerada a diferença entre o valor pago (ou a ser pago) pelas indenizações e aquele recebido pela Empresa LLX (atualmente Prumo Global) pelos aluguéis às empresas já interessadas em se instalar no Distrito industrial, em 2012, esse valor poderia atingir até $\mathrm{R} \$ 150$ milhões por ano ou até $\mathrm{R} \$ 3$ bilhões em 20 anos (MORAES, 2013).

12 Roberto Moraes chama atenção para a discrepância entre os valores propostos pela Empresa para as indenizações - de $\mathrm{R} \$ 1,90 \mathrm{o} \mathrm{m}^{2}$ - e aqueles recebidos a título de aluguel - $\mathrm{R} \$ 6,00$ o $\mathrm{m}^{2}$ (MORAES, 2012). Em matéria mais recente, intitulada "Primeira sentença da justiça sobre as desapropriações das terras do Açu confirma decreto, mas obriga a Codin a corrigir as indenizações aos agricultores para $\mathrm{R} \$ 37$, o m", Moraes (2019) enfatiza a alteração dos valores indenizatórios, que, só nesta ação, saltou para $\mathrm{R} \$ 19,7$ milhões, considerando o valor da terra e os juros e correção. Continuando, Moraes afirma que, considerando as centenas de processos contra a Empresa, estima-se que as indenizações podem chegar aos $\mathrm{R} \$ 4$ bilhões.

Novos Cadernos NAEA • v. 24 n. $2 \cdot$ p. 11-36 • maio-ago 2021 
2018, destina áreas contíguas ao perímetro do porto para usos que devem servir a interesses de ampliação do Complexo, funcionando como "reserva" estratégica legal (ASSAD, 2019).

O projeto de desapropriação foi questionado desde a primeira hora por parte dos camponeses organizados em sua Associação (ASPRIN). Em um primeiro movimento, a partir de uma ampla aliança e articulação política - em níveis local, nacional e internacional - enfatizando as violações praticadas contra os agricultores, acrescidas das denúncias de corrupção e de crime ambiental, a ASPRIN e seus aliados ${ }^{13}$ apresentaram denúncias nas mídias tradicional e alternativa, e, na esfera da Justiça (estadual e federal), contra a Codin e a empresa. Observa-se que as ações da ASPRIN tinham duas direções: uma primeira, que denunciava a ausência e/ou as baixíssimas indenizações e demandavam uma ação da justiça com relação à alteração dos valores do $\mathrm{m}^{2}$ desapropriado; e uma outra, que reivindicava o cancelamento do Decreto de desapropriação e a devolução imediata das terras aos agricultores.

Merece destaque a narrativa dos camponeses e seus parceiros no que se refere aos conflitos trazidos pelo Porto do Açu, anunciado como a redenção da Região Norte Fluminense, seja pela grande mídia nacional e pelas mídias locais; pelos grupos políticos, do governo e da oposição; setores empresariais e do comércio; sindicatos de trabalhadores; seja por pesquisadores vinculados às universidades e centros de pesquisa, demonstrando a hegemonia do discurso sobre a relevância do Porto para a "geração de empregos" e para o "desenvolvimento regional", dois clichês do discurso neoliberal.

Ao perderem seu meio de vida e de reprodução social-a terra-, uma parcela significativa dos agricultores e pescadores foi empurrada para o assalariamento, quase sempre em atividades informais e desprotegidas. No caso daqueles com idade mais avançada, restaram os programas da Assistência Social, em especial os Programas de Transferência de Renda, situação que evitaram durante toda uma vida ligada à agricultura familiar (COSTA, 2018). Cabe, aqui, uma breve reflexão sobre a relação entre expropriação e assistência social no País, já que esta não é a primeira e nem a única vez em que a Assistência Social Pública é apresentada

$\overline{13}$ Costa (2018) destaca o amplo arco de alianças em defesa deles, entre elas, a parceria com movimentos e organizações sociais, como o Movimento dos Trabalhadores Sem Terra (MST), o Movimento dos Pequenos Agricultores (MPA), a Pastoral da Terra, a Associação de Geógrafos Brasileiros (AGB), a Associação dos Juízes pela Democracia (AJD), as Igrejas, a Justiça Global, os professores das universidades públicas, o IFF/Campos, vereadores, deputados e sindicatos. Faz, ainda, uma ressalva especial com relação ao I e II Encontro das Resistências, realizados com os vitimados do Porto do Açu, em Conceição de Mato Dentro (MG) e em São João da Barra (RJ), respectivamente, as duas pontas de um mineroduto de mais de $500 \mathrm{~km}$ que desemboca no Porto do Açu. 
como saída para as sequelas mais imediatas da expropriação dos meios de vida. A pesquisa hemerográfica apontou situações bastante semelhantes sobre o papel de acomodação dos conflitos por parte dos programas de Assistência Social.

Os dados sobre a dinâmica do mercado de trabalho no município de São João Barra, no período de 2007 a 2017 (PEREIRA, 2018) — período de implementação e início das atividades do Porto do Açu — demonstram que nem as justificativas, nem as expectativas com relação à geração de empregos foram confirmadas. A partir de 2014, período de início das operações do Porto, houve queda nas contratações do município, o que pode indicar que tal atividade não gerou o número de empregos permanentes anunciados. Segundo informações dos representantes do Porto do Açu, a ocupação atual é de 4 mil trabalhadores (AUDIÊNCIA PÚBLICA..., 2019) no Complexo Portuário. É preciso chamar atenção, no entanto, para a desestruturação das atividades tradicionais ligadas à pequena agricultura, à pequena criação e à produção leiteira, com a expropriação dos pequenos agricultores do $5^{\circ}$ Distrito de São João da Barra.

\subsection{A RESISTÊNCIA DOS MORADORES DA MARGEM DA LINHA ÀS REMOÇÕES DO PROGRAMA "MORAR FELIZ"}

Em Campos, merece destaque o protagonismo dos moradores da Favela da Margem da Linha e sua resistência ao processo de remoção forçada realizado pela prefeitura, na implementação do seu programa de habitação popular, de 2009 a 2016. Cabe salientar que, em função das novas expectativas criadas pelo Complexo E\&P de petróleo e gás com a descoberta do pré-sal e pela instalação do megaporto do Açu, o município de Campos - pelo seu porte territorial, demográfico e logístico, pela sua infraestrutura e por consistir em um importante polo regional de comércio e serviços - reforçou a posição privilegiada com relação aos demais como local de residência, considerando os novos empregos criados pelos GIs instalados no NF. Essa expectativa de negócios em torno da moradia para os trabalhadores do Porto do Açu gerou uma euforia no mercado, transformando a cidade de Campos em um disputadíssimo objeto da especulação imobiliária por parte das grandes incorporadoras nacionais. Aliado a isso, a crise da agroindústria disponibilizou um imenso estoque de terras ociosas, que poderia vir a ser incorporado à agenda de ocupações do MST num futuro próximo ${ }^{14}$.

14 O período entre 1996-2006 foi de intensos conflitos pela terra na Região Norte Fluminense e na Microrregião de Campos, com a ocupação de terras improdutivas das usinas, protagonizada pelo MST, num primeiro momento e, depois, pela Federação Estadual dos Trabalhadores na Agricultura (FETAG). Atualmente, o NF conta com 17 assentamentos, sendo 11 no município de Campos, correspondendo a $65 \%$ do total. A área total dos assentamentos da região é de 23.982 ha, com $57 \%$ desse total em Campos, ou seja, 13.607 ha. 
Assim, aproveitando-se de uma conjuntura econômica de liquidez dos fundos de investimentos, em especial os imobiliários; de apoio político à construção civil e à expansão urbana como estratégias de criação de emprego; e, por fim, da disseminação da lógica de autossegregação entre os segmentos de maior renda como forma de enfrentamento da violência urbana, a cidade transformou-se em um imenso canteiro de obras: de um lado, as grandes incorporadoras com seus condomínios fechados; e, do outro, os conjuntos populares dos programas Minha Casa Minha Vida (MCMV) e Morar Feliz (MF) ${ }^{15}$.

Mesmo no contexto de implementação do programa MCMV, o município de Campos dos Goytacazes optou por um programa próprio de habitação popular, o Morar Feliz (Decreto Municipal no 55/2011), prometendo construir 10 mil moradias no período de 2009 a 2016, considerando o déficit local de 11.511 unidades em 2005, segundo a Fundação João Pinheiro. De acordo com o Programa, os critérios para concessão das casas populares são que os beneficiários sejam ocupantes de moradias irregulares em áreas de risco (definidos pela Defesa Civil); vulneráveis socialmente; e oriundos do Programa SOS Habitação. Orçado em $\mathrm{R} \$ 357$ milhões, só na primeira fase, a escolha por manter um programa habitacional com recursos próprios daria à municipalidade certa liberdade na direção de seu funcionamento.

Segundo Manhães e Arruda (2017, p. 10), "verificou-se uma rápida expansão urbana em direção a estas terras (das Usinas), abrindo margem para a especulação imobiliária, acarretando uma grande valorização e a transformação de antigas áreas rurais em 'áreas urbanas"'. Entre 1981 e 2014, foram construídos 32 condomínios horizontais fechados em Campos dos Goytacazes (MANHÃES; ARRUDA, 2017), entre outros empreendimentos, como a construção de hotéis de bandeira internacional, de estabelecimentos de atacado e varejo de megaempresas nacionais e internacionais, e de centros de logística de armazenagem e distribuição de mercadorias, que respondem pelas mudanças no uso do solo urbano, favorecendo a concentração fundiária e a especulação. Além da especulação imobiliária e da privatização do espaço público, os condomínios horizontais vêm provocando a ressignificação das áreas periféricas tradicionalmente habitadas pelas frações mais empobrecidas da classe que vive do trabalho, empurrando essa classe em direção às periferias das periferias.

Ao responder positivamente às pressões do mercado imobiliário sob a pretensão de eliminar as situações de "risco social", o poder público municipal

15 Os projetos do MCMV devem seguir toda uma normativa de acompanhamento social por meio dos Cadernos de Orientação do Trabalho Técnico Federal (COTS) e das diversas instruções determinadas pelo Ministério das Cidades, mas desconsideradas na implementação do Morar Feliz (AZEVEDO; TIMÓTEO; ARRUDA, 2013). 
realizou inúmeras remoções urbanas. Essas intervenções deixam claro um novo poder local, ou melhor, uma nova coalisão de classe na cidade de Campos, integrando as frações da burguesia vinculadas ao mercado imobiliário (incorporadoras, grandes construtoras, bancos e fundos de imobiliários) e aquelas representantes do setor agropecuário, em especial as famílias dos antigos usineiros/grandes proprietários de terra, mediadas pela ação do Executivo municipal e suas alianças político-eleitorais.

Segundo Chesnais (2003) e Harvey (2013), no novo regime de acumulação, de acumulação por espoliação, o sistema de crédito e o capital financeiro desempenham um papel relevante, comandando o processo de valorização sustentado na superexploração da força de trabalho e na transferência direta de grandes parcelas da produção para a esfera da especulação. Assim, o processo de acumulação por despossessão caminha, lado a lado, com o avanço da espoliação dos meios de vida, bem como com a mercantilização dos direitos e com a progressiva privatização das cidades.

Segundo Rolnik (2016), esse processo de valorização, que vem se apropriando das cidades, tem transformado as políticas de habitação em um setor econômico, mais do que em uma política social. Ainda segundo essa autora, o mais grave não é o acesso à habitação via crédito, mas a expansão do mercado na direção dos mais pobres, metamorfoseando em mercadoria e ativo financeiro algo historicamente definido como política social.

Durante o período de 2009-2016, a prefeita Rosinha Garotinho construiu 14 conjuntos habitacionais do Morar Feliz e entregou mais de 6.500 casas, sendo 5.426 apenas no primeiro mandato. Estima-se que, aproximadamente, mais de 20 mil pessoas tenham se deslocado dos seus lugares de origem para residir em outros bairros - muitas vezes em locais distantes, sem infraestrutura e sem segurança -, o que ocasionou, para além do próprio ato da remoção, prejuízos e danos de ordem material e emocional gravíssimos.

Mendes, Gomes e Siqueira (2014) destacam a ausência e/ou insuficiência dos equipamentos coletivos para atender os novos moradores. Nesta mesma direção, Santos (1998) chama a atenção para as periferias desérticas de bens e serviços coletivos e para a brutalidade do processo de urbanização sem direitos, negando o acesso dos mais pobres ao que ele chama de direito ao entorno. Ganhase a casa, mas não o direito à moradia. As manifestações coletivas, registradas pela pesquisa hemerográfica, denunciam a falta de vagas nas creches, nas 
escolas, nos postos de saúde, no transporte público, demonstrando a ausência de planejamento com a participação popular na condução do programa local de habitação popular, fortemente marcado pelo clientelismo ${ }^{16}$.

Além de remoções de inúmeras favelas, o MF também promoveu a concessão das "casinhas" - como foram popularmente nomeadas - às famílias que recebiam o benefício socioassistencial do aluguel social e àquelas de diversas localidades do município, consideradas em "situação de risco". "O termo 'área de risco' vem em substituição à expressão 'área carente' [...]; por meio de uma fala técnica, constrói-se uma cartografia do risco, como se a inserção de moradias em solos propensos a tais eventos fosse um risco autoimposto à vida" (VALÊNCIO, 2009, p. 35 apud MENDES; GOMES; SIQUEIRA, 2014, p. 43). Ainda segundo Valêncio, corrobora-se, com isso, a prática de remoções compulsórias, obscurecendo a dimensão política do processo em que o poder público municipal opta por uma determinada interpretação espacial da realidade local. Atualmente, o termo área de risco vem sendo usado também para designar as áreas mais expostas à violência urbana.

Findado o primeiro governo, a prefeita foi reeleita, em primeiro turno, com $70 \%$ dos votos válidos, confirmando a sua intenção de seguir com o programa MF, um dos seus principais cabos eleitorais. Porém, o segundo mandato, iniciado em 2013, seria marcado por dois fatores: o primeiro, a crise de 2012, cujos impactos na economia brasileira ameaçaram os programas sociais, sobretudo a partir de 2014; o segundo diz respeito às sequelas da primeira fase do MF, em especial ao deslocamento de populações residentes em áreas sob o comando de facções rivais para os mesmos conjuntos habitacionais. Longe de qualquer registro estigmatizador, a intenção é a de chamar atenção, mais uma vez, para a ausência de participação popular no MF e para o modo irresponsável como foram tratados os conflitos relacionados às disputas entre as facções pelo controle do mercado "de varejo" de drogas.

Os conflitos entre facções rivais, muitos deles armados, alteraram a sociabilidade cotidiana nos conjuntos do MF, construindo no imaginário popular uma associação entre o MF, violência e homicídios, o que contribuiu para aprofundar o processo de fragmentação social e de hierarquização, ambos fundados num profundo sentimento de estigmatização com relação ao outro, o da “casinha” (MOTA; MAMANI, 2012). Essa violência tornou-se o principal motivo

16 Mais tarde, o casal Garotinho e Rosinha seria denunciado por corrupção, tanto no caso do Programa Cheque - Cidadão, como no do Programa Morar Feliz (PMF). Este último integraria uma parte da Lava Jato, envolvendo a participação em propina por parte da construtora Odebrecht, responsável pelo PMF em Campos dos Goytacazes no governo Rosinha Garotinho (GAROTINHO..., 2019). 
das pessoas deixarem ou desejarem deixar o MF, principalmente nos conjuntos onde há enfrentamento entre facções rivais, o que fez aumentar o comércio (não oficial) das "casinhas". Além desse "troca-troca", há também a apropriação das "casinhas" pelo tráfico de drogas, geralmente daquelas pertencentes às pessoas oriundas de comunidades "dominadas" por facções rivais ou as que não aceitam a sua autoridade no território.

Observa-se que, até 2014, a moradia não aparecia como objeto das manifestações coletivas em nenhum município da Microrregião (CARVALHO; ALMEIDA, 2020). Uma hipótese seria o movimento de antecipação, realizado por parte dos governos populistas. Segundo Oliveira e Pedlowski (2012), o aumento do orçamento municipal - pelas transferências dos royalties e participações especiais - vai possibilitar ao governo local incorporar, na sua agenda política, um conjunto de intervenções na área social, com destaque para os programas de transferência de renda e de habitação popular ${ }^{17}$.

No que se refere à Favela da Margem da Linha, cabe registrar que ela foi a maior favela de Campos. Situada à margem esquerda da BR-101 (direção Rio-Campos) e entre esta e o leito da ferrovia, sua origem remonta a 1968, período caracterizado pela intensificação do processo de expropriação dos trabalhadores do campo, iniciado nos anos de 1950, e que se intensificou nas décadas seguintes, com as mudanças nas relações de trabalho. Nesse sentido, os relatos dos moradores da Margem da Linha sobre a ocupação do seu território coincidem com o contexto de expropriação do campo e da ocupação das áreas públicas - neste caso, as margens da linha da Rede Ferroviária Federal - por parte dos trabalhadores rurais das antigas Usinas do Queimado e Cupim, cujas sedes se situavam nas duas pontas da favela. Segundo os estudos de Pires (2005, p. 34), a Favela Margem da Linha "é considerada linear, estendendo-se ao longo de mais de $7 \mathrm{~km}$, que vai do limite do Parque S. Caetano, passando pela Tapera, até os limites da Usina Cupim, próximo ao subdistrito de Ururấ".

${ }_{17}$ Importante registrar que, durante o período em que Garotinho foi governador do estado do Rio de Janeiro, foram mantidas parcerias entre o município de Campos e a Companhia Estadual de Habitação do Estado do Rio de Janeiro (CEHAB-RJ), que resultaram na construção de 700 unidades habitacionais através do Programa de Moradia a R \$1,00. A partir da construção do conjunto da Chatuba, o governo municipal tomou para si a responsabilidade de executar, com recursos próprios, um ambicioso programa habitacional. A questão habitacional passou a ser o foco das políticas de assistência social em Campos, canalizando aproximadamente um montante anual de R $\$ 20$ milhões. O Programa Municipal de Habitação executado pela PMCG diferencia-se das experiências realizadas até a década de 1980, por não utilizar a capacidade de endividamento das famílias como um critério determinante na escolha dos potenciais beneficiários. As habitações são entregues gratuitamente aos beneficiários em regime de comodato (OLIVEIRA; PEDLOWSKI, 2012). 
Ainda de acordo com Pires (2005), a Favela Margem da Linha dividiase em três áreas, com características particulares: A (dos limites do Parque São Caetano à BR 101-Avenida Silvio Bastos Tavares); B (da Avenida Silvio Bastos Tavares até a Tapera); e C (que margeia a BR 101, indo até os limites da Usina Cupim).

A remoção da Favela da Margem da Linha em toda a sua extensão não se deu no mesmo momento. Em 2012, o governo priorizou a remoção das áreas B e C, áreas mais distantes do Centro, talvez pela sua situação de precarização, do risco em virtude da sua proximidade com a BR-101 e, também, em função da aceitação da remoção por parte dos seus moradores, deixando a parte $\mathrm{A}$, mais central, para o ano de 2014. De acordo com a pesquisa hemerográfica (20002017), não houve nenhum registro de protesto dos moradores dessas áreas por conta da remoção para o conjunto do MF Tapera 1 em 2012.

Segundo Mothé (2011), referindo-se aos moradores das áreas B e C da Margem da Linha, a proximidade espacial com a Tapera (área para onde os moradores seriam transferidos) fazia com que a maior parte dos moradores $(60 \%)$ já se considerasse parte do bairro para onde estavam sendo removidos. Além do mais, a remoção possibilitou que os moradores continuassem juntos.

Tais motivos, e mais as condições precárias das moradias e do entorno, favoreceram a remoção, o que não ocorreu com os moradores da parte A da Margem da Linha. Mothé (2011) sugere que a extensão da favela e sua linearidade acabaram promovendo realidades e experiências bastante distintas entre a parte A (mais central) e as partes B e C (já mais distante do Centro), o que pode explicar as diferentes reações quanto às remoções do MF. Ao contrário das partes B e C, a parte A da Favela da Margem da Linha está mais próxima do Centro e, portanto, do comércio, dos equipamentos públicos coletivos, do mercado de trabalho, não necessitando do transporte público para sua mobilidade, aspectos fundamentais para a classe trabalhadora e dos quais os moradores não queriam abrir mão.

Segundo pesquisa realizada por Mendes, Gomes e Siqueira (2014), 33,3\% desses moradores nasceram e cresceram na Margem da Linha, e 55\% mudaramse para a comunidade a fim de morar com/ou próximo a seus familiares. E mais, $54,9 \%$ dos entrevistados residiam no local há mais de 20 anos, a maioria em casas construídas em regime de autoconstrução.

Em setembro de 2012, a prefeitura deu início ao processo de marcação das casas a serem demolidas e ao registro das famílias que seriam transferidas para o MF de Ururaí II. Ao todo, foram marcadas 750 moradias, todas consideradas em "situação de risco" pela Defesa Civil. De acordo com uma pessoa entrevistada por Carvalho e Almeida (2020): 
A prefeitura veio e nem perguntou se a gente queria sair, eles praticamente impuseram que a gente saísse, ou saía ou ficaria sem casa, ou vai para aonde a gente colocar vocês, porque aqui tudo vai ser demolido. A gente não teve mais nada como aceitar ou não. Foi um processo louco e doído, porque se era para tirar, tinham que tirar todos. A gente foi na prefeitura, fizemos paralisação, uma manifestação. Eles tinham que nos colocar para viver com qualidade de vida, sem precisar remover, porque aqui não oferece risco. Aqui não tem risco para ninguém. Alegaram risco do trem, mas nós vivemos a vida toda com trem, eram tantas conversas fiadas [...]. Segundo relatos, foi por causa dos condomínios, porque as pessoas não querem pagar o valor do IPTU, porque está perto de uma comunidade e acham que perdem valor (CARVALHO; ALMEIDA, 2020, p. 9).

Sem diálogo com os moradores, no final de novembro de 2014, o governo deu início ao processo com a transferência das famílias para o MF Ururaí II, quando se verificou que não havia casas suficientes no novo conjunto do MF para todas as famílias. Sem lugar para ficarem, já que suas moradias haviam sido demolidas, a prefeitura concedeu o benefício do aluguel social para essas famílias, que, depois, foram transferidas para outro conjunto do MF, o Tapera II. Além de expressar a irresponsabilidade dos gestores, esse fato chama atenção também para o descaso para com a população.

Fica claro para os moradores a falta de intenção do governo de manter a comunidade no mesmo conjunto do MF, sem contar que o MF Tapera II, além de distante, ficava no "meio do nada". Isso contribuiu para dar fôlego à resistência dos moradores, aumentando o grupo daqueles que queriam permanecer na Margem da Linha. Impiedoso, o governo retaliou os que permaneceram resistindo, deixando-os entre os escombros e sem energia elétrica após a remoção parcial da comunidade. Este processo fortaleceu a organização da comunidade, que, junto com a Defensoria Pública, entrou com uma representação na Justiça Estadual, reivindicando o direito dos moradores de permanecerem no seu território, lugar que ocupavam há mais de 50 anos, questionando o diagnóstico da Defesa Civil, de "situação de risco", e o processo de remoção sem a participação dos moradores e sem a garantia de que os moradores ficariam no mesmo conjunto; direito que foi concedido após sentença judicial favorável.

Mendes, Gomes e Siqueira (2014) ressaltam que os moradores aceitariam a remoção desde que fosse confirmada a impossibilidade de realização de melhorias na própria comunidade; que toda a comunidade fosse removida para o mesmo local; e que este fosse próximo à Favela Margem da Linha. Para uma entrevistada abordada por Mendes, Gomes e Siqueira (2014, p. 52), “a prefeitura poderia pegar o dinheiro do Morar Feliz e arrumar a Margem da Linha. Arrumar as 
nossas casas aqui mesmo". Se, de um lado, a remoção arrancava as raízes criadas ao longo da vida, dificultava as oportunidades de trabalho - pela proximidade do local - e impedia a continuidade das sociabilidades construídas com a vizinhança e as instituições, de outro, ela representava a realização do sonho da casa própria, em situação menos precária do que a existente.

Do ponto de vista da especulação imobiliária, a localização da parte A da Favela da Margem da Linha representava a desvalorização das suas "mercadorias" e, por conseguinte, dos seus investimentos. Daí a rejeição a qualquer ação de melhoria na sua infraestrutura ou de remoção para uma área próxima, como queriam os seus moradores. Entre os inúmeros investimentos privados na vizinhança da favela, destacam-se o Boulevard Shopping, a implantação de duas torres de edifícios com mais de dez andares, um hotel de rede internacional e cinco condomínios horizontais fechados, até 2014, o que contribuiu para acelerar o processo de ocupação e de valorização daquele território e para estigmatizar a Margem da Linha como obstáculo a uma maior valorização. Entre 2009 e 2011, houve uma valorização fundiária de cerca de 70\% no Parque dos Rodoviários, bairro onde estão localizados o Boulevard Shopping e a Favela Margem da Linha. Além disso, apesar de grandes vazios urbanos no entorno do empreendimento (terras de propriedade da antiga Usina do Queimado), não se encontram ofertas expressivas de terrenos, o que evidencia a sua concentração nas mãos de grandes investidores para lançamentos imobiliários futuros (FARIA; GOMES, 2012).

Segundo uma moradora:

No início, a gente nem sabia sobre a remoção. Ficamos sabendo por acaso que a comunidade seria removida. Uma pessoa ouviu uma conversa que seríamos removidos. Ficamos dialogando com pessoal do governo, falaram que não sairíamos dessa maneira. Quando a gente menos esperou, marcaram a pedra fundamental em Ururaí, do Morar Feliz, daí falamos o quê? E eles vieram aqui (o poder público) e falaram que quem não fosse iria ficar sem casa, e as pessoas foram ficando com medo. Começamos a fazer o movimento social na comunidade, para poder falar o que acontecia. Veio o pessoal da UFF, IFF (arquitetura) e UENF, e nos deu apoio. Fizemos audiência pública no IFF e esquentou no dia. Tivemos apoio das faculdades, do Centro Juvenil São Pedro e entramos em contato com a defensoria pública. Eles (o poder público) vieram com tudo não respeitando nossos direitos, nem nossos vínculos, passando por cima. Nós até participamos do grito dos excluídos. Essa segregação deles, eles tiram o pessoal daqui e vai enfiando nos buracos dos buracos. Quer dizer, da periferia para a periferia, vai limpando a cidade, e higienizando, tirando os pobres da cidade. Falam da área de risco por causa da linha do trem que foi desativada, inventaram a tubulação de gás (aqui o pessoal usa gás encanado) e alagamentos. Tudo que eles começaram a falar caiu em contradição, eles arrumaram de tudo (CARVALHO; ALMEIDA, 2020, p. 9). 
Entre outros pontos já problematizados, a moradora refere-se ao pessoal dos condomínios, sugerindo um forte sentimento de estigmatização por parte destes com relação aos moradores da comunidade. Caldeira (1997) salienta que os enclaves fortificados, referindo-se aos condomínios horizontais fechados consumidos pelas classes médias e alta, em função da segurança e da exclusividade - sendo, portanto, espaços privatizados de moradia, consumo, lazer e trabalho -, vêm se constituindo uma nova modalidade de segregação socioespacial, alterando profundamente a configuração dos espaços urbanos. E mais, para Caldeira (1997), a cidade de muros não reforça a cidadania; antes, estimula a sua erosão, contribuindo, também, com o avanço do processo de privatização da cidade, pela sua captura pela racionalidade mercantil.

A resistência dos moradores da Margem da Linha à remoção não foi um ato imediato. Como demonstra o depoimento da moradora, ela foi sendo construída paulatinamente em função da complexidade da situação e da experiência de participação da comunidade. Na verdade, uma resistência é sempre uma construção gradual, considerando que, ao longo do processo, os sujeitos - neste caso os moradores - vão apreendendo novos significados e atribuindo novos sentidos ao processo.

Isso só foi possível porque, assim como na experiência dos agricultores do Açu, essa experiência também contou com um amplo arco de alianças, entre elas, movimentos, organizações sociais e instituições, como o Centro Juvenil, ligado aos Salesianos, as universidades públicas, o IFF, a Defensoria Pública, entre outros. Essas alianças permitiram que metade dos moradores do que restou da Favela da Margem da Linha após 52 anos permanecesse no lugar onde escolheram e construíram suas experiências e memórias, ainda que em condições precárias e de negação dos direitos. Cabe investigar como essa experiência marcou a sociabilidade dos moradores, em especial na sua capacidade de defender os seus interesses comuns.

\section{CONCLUSÃO}

A análise dos conflitos envolvendo os camponeses do Açu e os moradores da Favela da Margem da Linha em dois municípios da Microrregião de Campos dos Goytacazes/RJ chama atenção para um conjunto de mediações que compõem o recente processo de modernização da Região, iniciado com a descoberta do petróleo na Bacia de Campos e a sua exploração, nos anos de 1980. Ao mesmo tempo que esta nova atividade promovia um deslocamento na economia local, ela 
também promovia um novo poder local, sustentado em novas alianças políticas e econômicas, envolvendo, sobretudo, os chefes políticos dos municípios petrorrentistas e os agentes dos GIs. As experiências analisadas trazem à tona novos modos de governar e de gerir a "coisa pública", particularmente no que se refere às necessidades sociais dos subalternos.

A pesquisa mostra o modo como os GIs vêm atuando no território, apontando para a reconfiguração das suas relações socioespaciais e deslocando as arenas de decisão, em grande parte submetidas às negociações privadas e, muitas vezes, corruptas. Associado a isso, a cultura política clientelista amparada em orçamentos bilionários, em um contexto de pequena participação política, constitui um desafio à superação das relações de dependência e de construção de um espaço público mais participativo e democrático. Todavia, isso não se dá sem conflitos, como demonstra a pesquisa. De modo distinto das metrópoles e dos grandes centros urbanos, as resistências dos "de baixo" às novas formas de dominação na Região denunciam a ação dos GIs, do ponto de vista da garantia dos direitos sociais e ambientais e, principalmente, quanto ao papel assumido pelo Estado no contexto de avanço do neoliberalismo.

Buscando contribuir para a investigação das questões postas na introdução, o artigo identificou um conjunto de articulações multiescalares entre agentes políticos estaduais e empresariais, à escala internacional, com o beneplácito e a cumplicidade do poder local, para viabilizar o Porto do Açu, utilizando-se, de forma arbitrária, e mesmo ilegal, dos instrumentos jurídico-administrativos com apoio da força policial estadual - na expropriação de pequenos produtores e na transferência dos seus ativos, a terra produtiva, para as atividades rentistas dos proprietários do Porto.

No caso da população removida da Favela da Linha, as articulações se deram entre o Poder Público municipal, favorecido pelas rendas petrolíferas e pelos interesses de grandes agentes imobiliários, à escala nacional; dos proprietários de terra, herdeiros dos grandes fazendeiros e usineiros do ciclo do açúcar; dos grandes empresários nacionais e internacionais do setor hoteleiro e do atacado e do varejo; bem como dos maiores grupos nacionais do ramo de shopping center, voltados para a demanda de empresários e novos consumidores detentores das rendas geradas pelos GIs.

Ao mesmo, tempo, o artigo buscou mostrar que a análise da dinâmica capitalista contemporânea não é suficiente para dar conta das configurações particulares, muito menos da construção de resistências coletivas, que, em última instância, tornam os processos concretos repletos de tensão e de possibilidades 
diferenciadas de desfecho. Dessa forma, por meio da abordagem dos dois casos, percebeu-se que, dado o cenário geral do processo de acumulação capitalista contemporâneo, é necessário identificar, em cada caso particular, as mediações e ações que concretizam, ou não, as configurações desses processos no território.

As reflexões apontam no sentido da necessidade de pesquisa, análise e de aprofundamento do conhecimento dos processos particulares pelos quais os territórios vivem as tensões e contradições inerentes ao desenvolvimento capitalista contemporâneo, para que se vislumbrem as possibilidades de resistência e enfrentamento das mediações que tentam viabilizá-lo, a cada momento, em determinados territórios.

\section{REFERÊNCIAS}

AÇU: de 229 agricultores, menos de 5\% receberam indenização integral.

Defensoria Pública do Estado do Rio de Janeiro, Rio de Janeiro, 12 jun. 2017. Disponível em: https:/ / defensoria.rj.def.br/noticia/detalhes/4340-Acude-229-agricultores-menos-de-5-receberam-indenizacao-integral. Acesso em: 15 maio 2020 .

ALMEIDA, É. T. V.; CARVALHO, P. S. Mobilizações coletivas dos moradores de áreas periféricas em Campos dos Goytacazes/RJ: a cidade em debate. In: JORNADA INTERNACIONAL DE POLÍTICAS PÚBLICAS, 9., 2019, São Luís. Anais [...]. São Luís: UFMA, 2019. p. 1-12.

ASSAD, L. B. C. E. A produção do espaço e o zoneamento urbano: São João da Barra/RJ e o Porto do Açu. 2019. 104 f. Dissertação (Mestrado em Desenvolvimento Regional, Ambiente e Políticas Públicas) - Programa de Pós-Graduação em Desenvolvimento Regional, Ambiente e Políticas Públicas, Universidade Federal Fluminense, Campos dos Goytacazes, 2019.

AUDIÊNCIA PÚBLICA RJ-244 (1/3). [S. l.: s. n.], 19 fev. 2020. Publicado pelo canal de Wellington Abreu. Disponível em: https://www.youtube.com/ watch?v=IW0YfudADhE. Acesso em: 20 mar. 2020.

AZEVEDO, S.; TIMÓTEO, G.; ARRUDA, A. P. S. N. Habitação social e segregação espacial: implicações do Programa Municipal Morar Feliz, em Campos dos Goytacazes (RJ). In: ENCONTRO ANUAL DA ASSOCIAÇÃO NACIONAL DE PÓS-GRADUAÇÃO E PESQUISA EM CIÊNCIAS SOCIAIS, 37., 2013, Águas de Lindóia. Anais [...]. Águas de Lindóia: ANPOCS, 2013. p. 124. 
BRASIL. Lei $\mathbf{N}^{\mathbf{0}} \mathbf{9 . 4 7 8}$, de 06 de agosto de 1997. Dispõe sobre a política energética nacional, as atividades relativas ao monopólio do petróleo [...]. Brasília, DF: Presidência da República, [1997]. Disponível em: http:/ /www. planalto.gov.br/ccivil_03/leis/19478.htm. Acesso em: 11 jun. 2021.

CALDEIRA, T. P. Enclaves fortificados: a nova segregação urbana. Estudos Cebrap, São Paulo, v. 47, p. 155-176, 1997.

CARVALHO, P. S.; ALMEIDA, É. T. V. Experiências de resistência à remoção dos moradores da Favela da Margem da Linha. In: ENCONTRO INTERNACIONAL DE POLÍTICA SOCIAL, 8.; ENCONTRO

NACIONAL DE POLÍTICA SOCIAL, 15., 2020, Vitória. Anais [...]. Vitória: UFES, 2020. p. 1-15.

CHESNAIS, F. A “nova economia”: uma conjuntura própria à potência econômica estadunidense. In: CHESNAIS, F. et al. (org.). Uma nova fase do capitalismo? São Paulo: Xamã, 2003. p. 43-70.

\section{COSTA, A. M. A. O processo de expropriação das terras do Açu e a trajetória de lutas dos camponeses impactados pelo projeto Minas -} Rio. 2018. 266 f. Tese (Doutorado em Serviço Social) - Programa de PósGraduação em Serviço Social, Universidade Estadual do Rio de Janeiro, Rio de Janeiro, 2018.

CRUZ, J. L. V. Projetos nacionais, elites locais e regionalismo:

desenvolvimento e dinâmica territorial no Norte Fluminense entre 1970 e 2000. 2003. 340 f. Tese (Doutorado em Planejamento Urbano e Regional) - Instituto de Pesquisa e Planejamento Urbano e Regional, Universidade Federal do Rio de Janeiro, Rio de Janeiro, 2003.

EIG, dona do Açu, está ‘confiante’ com retomada do petróleo no país. Portos e Navios, Rio de Janeiro, 28 ago. 2019. Portos e logística. Disponível em: https:// www.portosenavios.com.br/noticias/portos-e-logistica/eig-dona-do-acu-estaconfiante-com-retomada-do-petroleo-no-pais. Acesso em: 20 abr. 2020.

FARIA, P. C. A; GOMES, M. A. S. O Boulevard Shopping no contexto das transformações socioespaciais em Campos dos Goytacazes. In: ENCONTRO NACIONAL DE GEÓGRAFOS, 17., 2012, Belo Horizonte. Anais [...]. Belo Horizonte: ENG, 2012. p. 46-47. 
GALDO, R. Norte Fluminense: fronteiras de uma região que vive entre a pobreza e a prosperidade. Jornal O Globo, 14 set. 2014. Disponível em: https://oglobo.globo.com/brasil/norte-fluminense-fronteiras-de-uma-regiaoque-vive-entre-pobreza-a-prosperidade-13932124. Acesso em: 20 abr. 2021.

GAROTINHO e Rosinha são suspeitos de superfaturar programa de moradia popular em Campos. G1 Norte Fluminense Inter TV, Campos dos Goytacazes, 3 set. 2019. Disponível em: https://g1.globo.com/rj/nortefluminense/noticia/2019/09/03/mp-rj-cumpre-mandado-de-prisao-contra-exgovernadores-rosinha-e-garotinho.ghtml. Acesso em: 20 abr. 2020.

HARVEY, D. O novo imperialismo. 7. ed. São Paulo: Loyola, 2013.

MANHÃES, V. R. R.; ARRUDA, A. P. S. N. A expansão dos condomínios horizontais privados em Campos dos Goytacazes. In: ENCONTRO NACIONAL DA ASSOCIAÇÃO NACIONAL DE PÓS-GRADUAÇÃO E PESQUISA EM PLANEJAMENTO URBANO E REGIONAL, 17., 2017, São Paulo. Anais [...]. São Paulo: ENANPUR, 2017. p. 1-20.

MARQUES, U. Injustiça e indignação. Jornal Terceira Via (Online), Campos dos Goytacazes, 5 fev. 2017a. Região. Disponível em: https://www. jornalterceiravia.com.br/2017/02/05/injustica-e-indignacao/. Acesso em: 03 jun. 2020.

MARQUES, U. Um tombo de R\$ 2 bilhões. Jornal Terceira Via (Online), Campos dos Goytacazes/RJ, 12 fev. 2017b. Geral. Disponível em: https:/ / www.jornalterceiravia.com.br/2017/02/12/um-tombo-de-r-2-bilhoes/. Acesso em: 03 jun. 2020.

MENDES, J. T. N.; GOMES, M. A. S.; SIQUEIRA, A. M. M. Políticas públicas, moradia popular e o programa morar feliz em Campos dos Goytacazes-RJ: uma análise acerca da favela margem da linha. Revista Libertas, Juiz de Fora, v. 14, p. 1-20, 2014.

MORAES, R. R\$ 150 milhões anuais de aluguel para 4 empresas no Açu. Blog do Roberto Moraes, Campos dos Goytacazes, 04 jun. 2012. Disponível em: http://www.robertomoraes.com.br/2012/06/r-150-milhoes-anuais-de-aluguelpara-4.html. Acesso em: 11 jun. 2021.

MORAES, R. Valor da terra no Açu: $\mathrm{m}^{2}$ de aluguel valendo o triplo do valor de compra/indenização. Blog do Roberto Moraes, Campos dos Goytacazes, 08 abr. 2013. Disponível em: http://www.robertomoraes.com.br/2013/04/valorda-terra-no-acu-m-de-aluguel.html. Acesso em: 11 jun. 2021. 
MORAES, R. Primeira sentença da justiça sobre as desapropriações das terras do Açu confirma decreto, mas obriga a Codin a corrigir as indenizações aos agricultores para $\mathrm{R} \$ 37, \mathrm{o} \mathrm{m}^{2}$. Valor dessa sentença $\mathrm{R} \$ 19$ milhões. Blog do Roberto Moraes, Campos dos Goytacazes, 20 mar. 2019. Disponível em: http://www.robertomoraes.com.br/2019/03/primeira-sentenca-da-justicasobre-as.html. Acesso em: 11 jun. 2021.

MOTA, C. G. S.; MAMANI, H. A. Segregação interna e criminalização: o caso da favela e o conjunto habitacional Matadouro em Campos dos Goytacazes/RJ. Revista Libertas, Juiz de Fora, v. 12, n. 2, p. 1-20, 2012.

MOTHÉ, N. G. Dinâmica socioespacial em zona de expansão urbana: os impactos da implantação de novos empreendimentos na área ao entorno da avenida Sílvio Bastos Tavares em Campos dos Goytacazes/RJ. 2011. 124 f. Dissertação (Mestrado em Políticas Sociais) - Programa de Pós-Graduação em Políticas Sociais, Universidade Estadual do Norte Fluminense, Campos dos Goytacazes, 2011.

OLIVEIRA, J. C. P.; PEDLOWSKI, M. A. Estado e programas municipais de habitação popular em Campos dos Goytacazes (RJ). Análise Social, Coimbra, v. XLVII (3º), n. 204, p. 656-682, 2012.

PEREIRA, G. V. O Porto do Açu e o município de São João da Barra RJ: impactos na dinâmica socioeconômica - 2007 a 2017. 2018. 83 f.

Dissertação (Mestrado em Desenvolvimento Regional, Ambiente e Políticas Públicas) - Programa de Pós-Graduação em Desenvolvimento Regional, Ambiente e Políticas Públicas, Universidade Federal Fluminense, Campos dos Goytacazes, 2018.

PIQUET, R.; CRUZ, J.; VILANI, R. (org.). O desafio da abundância: 10 anos do BPR\&R-Boletim Petróleo Royalties e Região. Rio de Janeiro: Garamond, 2013.

PIRES, B. O. Segregação sócio-espacial e qualidade ambiental: o caso da Favela Margem da Linha. 2005. Monografia (Licenciatura em Ciências Sociais) - Centro de Ciências do Homem, Universidade Estadual do Norte Fluminense, Campos dos Goytacazes, 2005.

RAMOS, T. T. A geografia dos conflictos sociais da América Latina e Caribe. Biblioteca Virtual CLACSO, [s. l.], p. 1-40, 2003. Disponível em: http:/ / bibliotecavirtual.clacso.org.ar/ar/libros/becas/2002/mov/tramon.pdf. Acesso em: 04 jun. 2020. 
ROLNIK, R. "Moradia se tornou sinônimo de mercadoria", diz a ex-relatora da ONU Raquel Rolnik. [Entrevista cedida a] Camilla Hoshino e Thiago Hoshino. Brasil de Fato, Curitiba, 16 ago. 2016. Geral. Disponível em: https:/ /www. brasildefato.com.br/2016/08/16/moradia-se-tornou-sinonimo-de-mercadoriadiz-a-ex-relatora-da-onu-raquel-rolnik. Acesso em: 21 jun. 2017.

SANTOS, M. O espaço do cidadão. 4. ed. São Paulo: Nobel, 1998.

TAVARES, V. Camponeses do Porto do Açu, no RJ, pedem fim do decreto que expropriou suas terras. Brasil de Fato, São João da Barra, 15 maio 2017. Geral. Disponível em: https://www.brasildefato.com.br/2017/05/15/camponeses-doporto-do-acu-no-rj-pedem-fim-do-decreto-que-expropriou-suas-terras. Acesso em: 03 maio 2019.

VAINER, C. B. Planejamento territorial e projeto nacional: os desafios da fragmentação. Revista Brasileira de Estudos Urbanos e Regionais, Brasilia, DF, v. 9, n. 1, p. 1-15, 2007. 